\title{
DESIGNING A TOURISM RECOMMENDER SYSTEM BASED ON LOCATION, MOBILE DEVICE AND USER FEATURES IN MUSEUM
}

\author{
MAEDE KiAni SARKALEH, MEHREGAN MAHDAVi AND MAHSA BANiARDALAN
}

Department of Computer Engineering, University of Guilan, Rasht, Iran

maedeh.kiani@gmail.com, mahdavi@guilan.ac.ir, mahsa_ardalan@yahoo.com

\begin{abstract}
Today, mobile devices are widely used by many tourists. They can use mobile for accessing information about all sightseeing around the world. On the other hand, it seems essential to personalize the content due to diversity of learners and variation of the tools they use. On the whole, the goal for personalization is to suggest a collection of comprehensive activities, taking into consideration factors such as location, user preferences and interests and so on. One of the applications of recommender systems is in tourism industry. Mobile devices can be used in sites such as museums. Demands of different people such as students, tourists and ordinary people can be met in spite of their diverse features and preferences. The purpose of this paper is to give a model which is able to recommend new locations to visitors in a museum while the visitor is given essential information about the certain features of the suggested site.
\end{abstract}

\section{KEYWORDS}

Recommender System, Location, Content Personalization, Mobile Device, User features

\section{INTRODUCTION}

Mobile devices have removed the location limitation such that one can personalize and suggest content in suitable form to him or her while considering the environment where the person is. For example, the tool can be used to obtain updated information about sightseeing around the world. The information can be shared with other users interactively. There are certain challenges in this area such as lack of an efficient model, diversity of information and the reality that the information is not collected in a central server [1].

Personalization process is fulfilled using the information obtained from learner. On the whole, the goal for personalization is to suggest a collection of comprehensive activities taking into consideration factors such as location, user preferences and interest and so on [2]. Personalization is performed through two methods: adjusting the learning services with learner's features such as learning methods, demands, situations, efficiencies, preferences and criteria; learning system conformation with learner's surroundings. Interrelation between user and user with the nearest neighborhood algorithm is used by most personalized systems. User-user interrelation is resulted from statistics and figures which signify the interrelations between variants and it is used to measure the model efficiency. In recommender systems, the interrelation is used to measure the rate of similarities between two users and to identify the users who are expected to be categorized. 
International Journal of Managing Information Technology (IJMIT) Vol.4, No.2, May 2012

As you know, there are a lot of diversities for mobile systems and applications of awareness of content. Awareness of content is an important feature for the recommender systems. Some aspects have been mentioned by Shilit et al: "Where are you? With whom? Which sources are near you? "Taking into account the traditional location of the user and his or her companions and how the near sources are obtained, significantly increases the applications of mobile system. In [13], instead of traditional methods which use only two dimensions of user and product, multidimensional methods are used.

When tourists arrive in a country, they need to pay for such things as food, hotel, transport, entertainment, museum and sightseeing visit. The currency the tourists bring into the visited country, leads to economic vigorous grow or so called covert export. Museum is one of tourist attractive sites in which learning content can be represented as an environment adjusted and suitable personalized form using advanced technologies such as mobile, laptop, PDA and so on in order that the tourist can be attracted to the system and other museums as well.

The organization of this paper is as follows: in Section two, former investigations are presented. Section three gives the suggested model in detail. The model is evaluated in Section four. The conclusion is given in the Section five.

\section{LITERATURE REVIEW}

In mid 1990s, the investigation about recommender systems began, focusing clearly on pricing. The issues were lowered by user defined formulas for estimated rates. The estimations were performed based on user defined ratings for items and other conventional information. Therefore, items with the highest rates were suggested to user. $\mathrm{C}$ signifies as all users and $\mathrm{S}$ is defined as all possible items such as books, film, restaurants and so on that can be suggested to user. S can be very extensive, amounting to hundreds, thousands or millions items for any user. For example, book or CD suggested items may reach to millions.

Collaborative filtering process for suggestion is the advanced technology now used in recommender systems leading to simpler and more quickly suggestions. Former recommender systems used collaborative filtering to predict a certain product rating in view of a certain user. There are two types of collaborative filtering: user-defined and item -based. The item-based collaborative filtering focuses on acquired items similarities rather than users " and is now prevalent and has high scalability and is suitable for great data collections [4].

Content-based filtering can also be used to suggest the present products which are preferable in view point of user. These systems use profiles which have been obtained from user. Profile represents information about the user and her or his interests. User's interests are measured based on items ratings. The search engine processes the former ratings of user along with unrated ones and it compares the similar features and finally suggested ones are presented [5].

Some of existing products are not purchased regularly so their purchase is regarded as very risky (such as financial services, car, electronic instruments and tourist services). In this case, recommender system so called knowledge-based recommender needs to comprehend deeply the user's demands to suggest helpful and accurate cases to the user [6]. Each type of recommender system benefits a certain advantages and disadvantages. Hybrid recommender system consists of two or more types of recommender systems to remove the disadvantages and to increase efficiency, capability and reliability of suggestion [7]. Many tourist guidance systems use content-based models. The system designed in [8] uses the information which is collected based on user's preferences and its content information includes location, elapsed time in the distance, the direction of the selected path, personal preferences and various user systems. Buchman and Hinze designed a system which suggested information about the sightseeing to tourists [9] and its 
content information included user location, present time, interests and such information about sightseeing as their locations, types and similarities. Other system called Cyber guide has been designed for tourism industry [10]. This system acts as human guide and uses PDA and GPS to give service to tourists in a site. Other system designed in [1], called Murshid uses Google Map as a visual guide. It is a content intelligent system which uses user location information, his or her interests, job and time schedule. Location-based and content intelligent recommender system uses content information such as location, time and so on and it is applied in restaurants $[11,12$, and 13], tourism industry [14] and commercial systems. Many investigations have been performed about content to suggest suitable services to users and certain recommender systems are introduced in brief in table 1 .

Table 1. Some existing context-aware recommender systems

\begin{tabular}{|c|c|c|c|c|c|c|}
\hline & $\begin{array}{c}\text { MIT } \\
\text { Media } \\
\text { Lab }\end{array}$ & $\begin{array}{c}\text { National } \\
\text { Tsing Hua } \\
\text { Univ. }\end{array}$ & $\begin{array}{c}\text { Telematica } \\
\text { Institute }\end{array}$ & $\begin{array}{c}\text { Fu-Jen } \\
\text { Univ. }\end{array}$ & $\begin{array}{c}\text { Telematica } \\
\text { Institute }\end{array}$ & Murshid \\
\hline $\begin{array}{l}\text { Recommenda } \\
\text { tion type }\end{array}$ & Restaurant & Restaurant & $\begin{array}{c}\text { Travel } \\
\text { information }\end{array}$ & $\begin{array}{c}\text { Commerci } \\
\text { al }\end{array}$ & $\begin{array}{l}\text { Tourism } \\
\text { industry }\end{array}$ & $\begin{array}{l}\text { Tourism } \\
\text { industry }\end{array}$ \\
\hline $\begin{array}{c}\text { Context } \\
\text { information }\end{array}$ & Location & $\begin{array}{l}\text { Location, } \\
\text { Time, } \\
\text { Weather }\end{array}$ & $\begin{array}{l}\text { Location, } \\
\text { Time, } \\
\text { Weather, } \\
\text { Shopping } \\
\text { list, } \\
\text { Schedule }\end{array}$ & $\begin{array}{l}\text { Location, } \\
\text { Time, } \\
\text { Fare, } \\
\text { Contents }\end{array}$ & $\begin{array}{l}\text { Location, } \\
\text { Time, } \\
\text { Weather, }\end{array}$ & $\begin{array}{l}\text { Location, } \\
\text { profile, } \\
\text { Time, user } \\
\text { interaction }\end{array}$ \\
\hline $\begin{array}{c}\text { Recommenda } \\
\text { tion method }\end{array}$ & $\begin{array}{c}\text { Interaction } \\
\text { between } 2 \\
\text { agents }\end{array}$ & $\begin{array}{c}\text { Search } \\
\text { after } \\
\text { requesting }\end{array}$ & $\begin{array}{l}\text { Variable } \\
\text { prediction } \\
\text { strategy }\end{array}$ & $\begin{array}{c}\text { Neural } \\
\text { network } \\
\text { learning }\end{array}$ & $\begin{array}{c}\text { Variable } \\
\text { predictor } \\
\text { strategy }\end{array}$ & $\begin{array}{c}\text { reasoning } \\
\text { engine, } \\
\text { J2ME }\end{array}$ \\
\hline Device & PDA, GPS & $\begin{array}{c}\text { Pocket PC, } \\
\text { GPS }\end{array}$ & $\begin{array}{c}\text { Mobile } \\
\text { phone, GPS }\end{array}$ & $\begin{array}{l}\text { Mobile } \\
\text { hone }\end{array}$ & $\begin{array}{c}\text { Mobile } \\
\text { phone, GPS }\end{array}$ & $\begin{array}{c}\text { Mobile } \\
\text { phone, } \\
\text { GPS, } \\
\text { Google } \\
\text { map }\end{array}$ \\
\hline
\end{tabular}

\section{CONTENT PERSONALIZATION}

Although there are various features for personalization, we plan to deal with significant as well as efficient ones such that their complications neither result in lower system speed in terms of real time response to user nor it fails to meet the user's essential needs.

Since museum visitors significant features for categorization are knowledge level, ethnic language and more important of all, a lot of tools and instruments the visitors use to acquire the contents of artistic works, so the recommender system must take these features into account. The figure 1 shows the personalization process. 


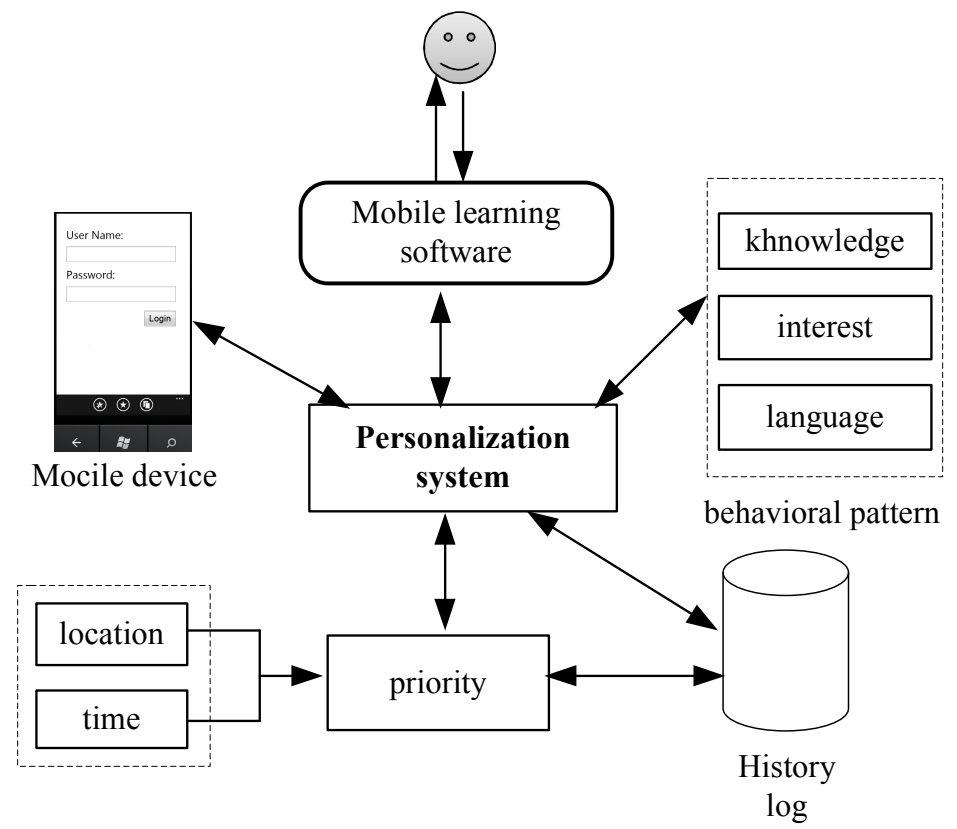

Figure 1. The personalization process

\subsection{Feature-Based Personalization}

- Knowledge Level: The prevalent knowledge level of learner can be assessed by tests and can be scored qualitatively (beginner, middle, advanced) and quantitatively (0-10). At the beginning, the learner is not identified by the system and it needs to pose self- teaching questions in order to identify the learner and to update the knowledge level of the learner consecutively.

- The preferences and interests can be similarly categorized. If learner is low interested, the system can give a general outline to the learner. If the learner is interested in the subject, the system can present detailed information. It is noted that at the beginning, the interest level of learner is null and it can be updated over time. The learner's preferences show how the learner desires to acquire the content (various multimedia such as audio, video, animation, text and so on which can be represented automatically).

- The language of visitor: The exhibition content must be adjusted to the native language of foreign visitors (English, Arabic, French, etc.)

\subsection{Personalization based on User's Mobile Device}

Today, various mobile technologies are consecutively growing all around the world. A lot of electronic services can be noted with many applications [16] including network-based mobile learning, wireless connections and mobile devices such as notebooks, mobile phone, personal communication system (PCS) and personal digital assistant (PDA) [17]. The features of mobile devices include mobility, independency, singularity, and accessibility. These features have changed learning model. The singularity of mobile learning allows learner to personalize the learning in accurate time and place and to enrich and diversify the learning content as much as possible.

In a museum, visitors bring diverse mobile devices with themselves so the exhibition must be represented in diverse personalized forms such as audio, video, text and animation, compatible 
International Journal of Managing Information Technology (IJMIT) Vol.4, No.2, May 2012

with visitor's mobile devices. Other possible compatibilities include multilingual support, diverse power consumption in Watt, the scale of exhibition screen, multimedia formats support (text, audio and video), search capability, user interaction compatibility, processing rate, RAM and its speed, connection technologies such as Bluetooth, 3G, Wi-Fi, IrDA and GPRS. A visitor who uses a regular mobile phone is able to receive information in animation format but only text format is available for her or him; however, another visitor who uses IPoD is able to receive the information about e.g. an animal life in video and animation formats, not available in the museum.

\subsection{Personalization based on user location}

Location-based services are value added ones in which position information is used to present diverse and interesting services to user including emergency services, vehicle navigation systems, tourist broadcasting services, searching in country- wide or urban sites data banks using map.

Geographic Position System (GPS) works based on satellite tracking and allows user to locate every point on the globe accurately. Mobile learning can be conducted through tracking by GPS. The GPS data can define three concepts: users, locations and activities in a certain site [18].

Another facility is communication network (BSC and BTS).BTS is responsible for exchanging radio waves with mobile unit as well as control and exchange data with BSC. BTS consists of independent transceivers, providing aerial and radio connection with mobile unit. BTS is the smallest unit of service provider in mobile radio network, supporting the certain region of the network called cell. BTS is designed to support higher radio coverage in roads or where the signal is weak and to meet traffic needs and its regular range in a smooth region is $30-35 \mathrm{KMs}$ but it is $20 \mathrm{KMs}$ in practice.

Radio Frequency Identification (RFID) is one of modern tracking technologies to locate user. This system identifies mobile and static objects by radio waves. In this new method, certain tags are used to store data. The data would be restored when needed [19]. The smart tag can be embedded inside electronic and non electronic products, animals and human body. The tag can be identified via transceiver waves in any time and place. RFID is now used for tracking vehicles, people, objects, security, transaction register and so on.

Google Map is another method in which the map can be efficiently downloaded and stored for future use. In its new versions, maps can be illustrated two and three dimensionally and it is possible to search the locations, to mark the interested points on the map, to give support for such services as Street View and My Tracks and audio guide.

\section{The Suggested Model (Process of Recommending New Site to VISIT IN A MUSEUM)}

Tourist attract is regarded as very significant and essential target for any state. Mobile devices can be used in such places as museums thanks to new technologies and the needs of different groups of people such as students, tourists, and ordinary people can be met via these technologies.

GPS can be used to track the visitors inside the museum and three concepts (user, location and activities) can be derived. One can usually see a lot of artistic works in a museum in many parts and shelves belonging to diverse fields of science. When a visitor visits a museum, recommender system must have a clear understanding of what the visitor needs to know as a learner and what seems attractive to the visitor and which part of the museum would be interesting for the visitor and should be offered to him or her.

Three behaviors of visitor (the visited place, preference for visit and amount of time spent in each visit) are identified after visitor visited the artistic works. This process is conducted via GPS. The 
collected data derived from the process is stored in a so called former visitors' data base in order to be used for later visitors. Recommender system suggests a place to next visitor based on former similar existing data.

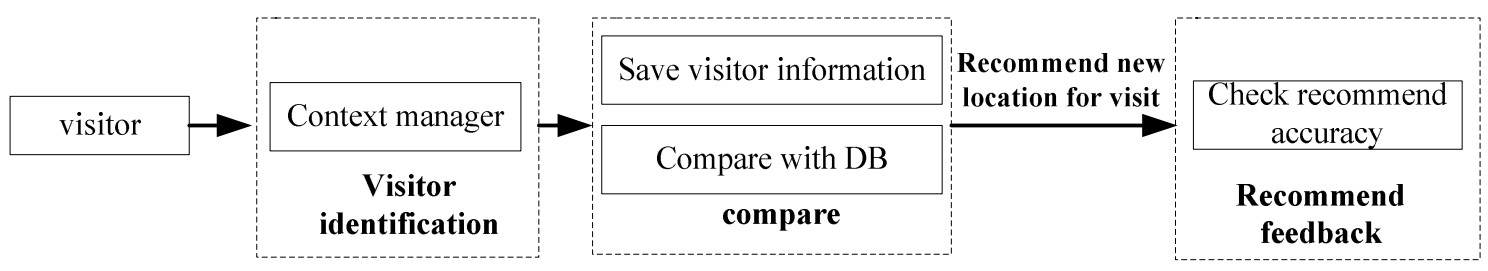

Figure 2. Process of suggesting new place to visit

Figure 2 shows the process of recommending a visitor a new place to visit. The suggested model steps are as follows:

- Step 1. Visitor identification: Content manager module is responsible for collecting content. The existing user's content must be delivered to the next step for process. The time and date are also restored from the mobile devices. At first, information about visitor is collected in order that improved personalization can be done efficiently. Figure 2 shows the content used in the model.

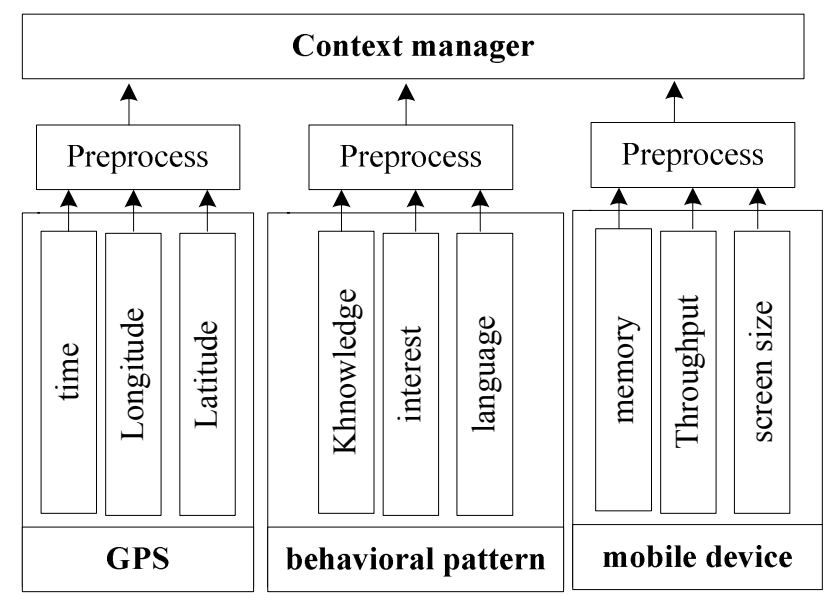

Figure 3. Content information

- Step 2. Comparison: It has two sections. 1. Storing the visitor information: The data derived from the user is stored implicitly in data base with lowest interruption for user. Recommender system can suggest next location to visit based on this data. 2. Comparing visitor's information with the information of former visitors in data base and suggesting next location to visit based on former and later visitors similarities.

- Step 3. Recommend feedback: The question is whether the suggestion has been acceptable for user or not. The answer would be available when the suggested place is compared with the visited one and then the quality of system can be evaluated on this basis. 
International Journal of Managing Information Technology (IJMIT) Vol.4, No.2, May 2012

\section{ASSESSMENT}

It is important to select suitable factors for evaluation such as cross assessment method, accuracy and restoration. Cross assessment method is used to determine the quality of a classifying tool and some learning data is used as a test set. For example, $90 \%$ of data is used as learning data and the remaining $10 \%$ is used to test the method. Accuracy is measured based on the number of accurately classified samples. The accuracy rate and the restoration rate for each classifier are assessed after learning and testing processes and identifying the class of each sample. The accuracy and restoration rates can be measured. The performance of classifier is judged based on the rate of any class. In fact, higher accuracy and restoration in restoring data are used to measure accuracy of various algorithms as well as for classifying methods.

First certain data is intended as learning data for the system and then the suggested model is assessed. Another data set is intended for testing the system. It is essential to collect all data to find whether the next visited place would be the same suggested one by the system or not.

\section{CONClusions}

In this paper we explored certain recommender systems. Then, a model was suggested as a recommender system to offer visitors a new location to visit. Due to diversity of visitors in terms of their mobile device and variation of networks, content personalization is essential. Locationbased services use GPS facility to track people based on the data derived about three concepts of user, location and activities in a certain site. Then, the suggested model can be used for visitors in practice.

\section{REFERENCES}

[1] L. Hajesmaeili, Z. Borhanifard \& M. araste (2010) E Commerce, Tehran, adabestan.

[2] A. A. Economides, (2008) "Personalization for Location-Based E-Learning", The Second International Conference on Next Generation Mobile Applications, Services, and Technologies, pp. 247-253.

[3] A. A. Economides (2009) "Requirements of mobile learning applications", International Journal of Innovation and Learning, Vol. 5, No. 5, pp. 457-479.

[4] T. H. Brown (2003)"The role of m-learning in the future of e-learning in Africa?", presentation at the $21^{\text {st }}$ ICDE World Conference.

[5] A. Echtibi, M. J. Zemerly, J. Berri (2009) "A Service-Based Mobile Tourist Advisor", International Journal of Computer Information Systems and Industrial Management Applications (IJCISIM), Vol.1, pp.177-187.

[6] A. K. Dey, G. B. Abowd (1998) "A Conceptual Framework and a Tool Kit for Supporting The rapid Prototyping of Context aware Application".

[7] A. Jappinen, J. Nummela, T. Vainio, M. Ahonen (2004) "Adaptive Mobile Learning Systems - The Essential Questions from the Design Perspective", In the Proceedings of MLearn2004, Roma, Italy, pp.109-112.

[8] M. Yudelson, T. Gavrilova, P. Brusilovsky (2005) "Towards user modeling meta-ontology", Proc. of 10th International User Modeling Conference, Springer Verlag, pp. 448-452.

[9] A. A. Economides (2008) "Context-aware mobile learning", the open Knowledge Society, A computer Science and Information Systems Manifesto, pp. 213-220, September 24-26.

[10] Kinshuk, M. Chang, S. Graf, G. Yang (2009) "Adaptivity and Personalization in Mobile Learning", Annual Meeting of the American Educational Research Association, San Diego, CA, April 13-17. 
International Journal of Managing Information Technology (IJMIT) Vol.4, No.2, May 2012

[11] V. W. Zheng, B. Cao, Y. Zheng, X. Xie, Q. Yang (2010) "Collaborative Filtering Meets Mobile Recommendation: A User-centered Approach", Association for the Advancement of Artificial Intelligence (www.aaai.org).

[12] T. Karygiannis, B. Eydt, G. Barber, L. Bunn, T. phillip (2007) "Guidance for Securing Radio Frequency Identification Systems" National Institute of Standards and Technology Gaithersburg.

[13] K.S. Huang, Tang (2008) "S.M., "RFID Applications Strategy and Deployment in Bike Renting System", Department of Information Management, National Yunlin University of Science and Technology, No. 123, University Road, Douliou, Yunlin, Taiwan, R. 0. C.

[14] J. Gavin (2007) "Mobile Phone Web Users Nearly Equal PC Based Internet Users in Japan", comScore. From http://www.comscore.com.

[15] B. Schilit, N. Adams, R.Want (1994) "Context-aware computing applications". IEEE Workshop on Mobile Computing Systems and Applications (WMCSA'94), Santa Cruz, CA, US: 89-101.

[16] M. Al Ali, J. Berri, J. Zemerly (2008) “Context-Aware Mobile Muslim Companion”, Proc. of the 5th Int. Conference on Soft Computing as a Transdisciplinary Science and Technology, Context Aware Mobile Learning Workshop, Cergy Pontoise, France, pp. 553-558, 27 Oct - 1.

[17] A. Pashtan, R. Blattler, A. Heusser, P. Scheuermann (2003) "CATIS: A Context-Aware Tourist Information System”, Proceedings of the 4th International Workshop on Mobile Computing, Rostok, June, pp.1-8.

[18] L A. Hinze, G. Buchanan (2005) "Context-awareness in Mobile Tourist Information Systems: Challenges for User Interaction”, Int. Workshop on Context in Mobile HCI, Salzburg.

[19] A. Garcia-Crespo, et al. (2009) "SPETA: Social pervasive e-Tourism advisor", Telematics and Informatics, vol. 26, pp. 306-315.

[20] G. Tewari, J. Youll, P.Maes (2003) "Personalized location-based brokering using an agent-base intermediary architecture”, Decision Support Systems 34, pp. 127-137.

[21] H. Tung, V. Soo (2004) "A personalized restaurant recommender agent for mobile e-service" IEEE International Conference on e-Technology, e-Commerce and e-Service (EEE'04), pp. 259-262.

[22] L M. Park, J. Indulska, and S. Cho (2007) "Location-Based Recommendation System Using Bayesian User's Preference Model in Mobile Devices”, LNCS 4611, pp. 1130-1139.

[23] M. Setten, S. Pokraev, J. Koolwaaij (2004) "Context-aware recommendations in the mobile tourist application COMPASS" AH2004, pp. 235-244.

[24] S. Yuan, Y. Tsao (2003) "A recommendation mechanism for contextualized mobile advertising", Expert Systems with Applications 24, pp. 399-414.

[25] T. Horozov, N. Narasimhan, V. Vasudevan (2006) "Using location for personalized POI recommendations in mobile environments", SAINT 2006, pp. 124-129.

[26] R. J. Mooney, L. Roy (2000) "Content-based book recommending using learning for text categorization”, Proceeding of the fifth ACM conference on Digital libraries Publisher, ACM Press, pp. 195-204.

[27] Robin Burke (2000) "Knowledge-based recommender systems", Encyclopedia of Library and Information Systems.

[28] Robin Burke (2002) "Hybrid recommender systems: Survey and experiments", User Modeling and User-Adapted Interaction, Vol. 12, No. 4, pp. 331-370.

[29] G. Adomavicius, R. Sankaranarayanan, S. Sen and A. Tuzhilin (2005) "Incorporating Contextual Information in Recommender Systems Using a Multidimensional Approach", ACM Transactions on Information Systems, Vol. 23, No. 1, pp. 103-145.

[30] A. Felfernig, S. Gordea, D. Jannach, E. Teppan, and M. Zanker "A Short Survey of Recommendation Technologies in Travel and Tourism”, ÖGAI Journal, Vol. 25 No. 2. 
International Journal of Managing Information Technology (IJMIT) Vol.4, No.2, May 2012

[31] J. Wolf, C. Aggarwal, K. Wu,., \& P. Yu, (1999) "Horting Hatches an Egg: A New Graph-Theoretic Approach to Collaborative Filtering", In Proceedings of ACM SIGKDD International Conference on Knowledge Discovery \& Data Mining, San Diego, CA.

[32] J. Breese, D. Heckerman \& C. Kadie (1998) "Empirical Analysis of Predictive Algorithms for Collaborative Filtering", In Proceedings of the $14^{\text {th }}$ Conference on Uncertainty in Artificial Intelligence (UAI-98), pp 43-52.

[33] B. Sarwar, G. Karypis, J.A. Konstan, \& J. Reidl, (2001) "Item-based Collaborative Filtering Recommendation Algorithms", Proceedings of the Tenth International Conference on World Wide Web, pp. 285 - 295. 